\title{
Metateatro, risa y melancolía en La venta de Francisco de Quevedo
}

\section{Marcela Beatriz Sosa}

Universidad Nacional de Salta - Instituto de Investigaciones en Ciencias Sociales y Humanidades, Argentina sosamar57@gmail.com

\begin{abstract}
Resumen
El teatro barroco hispánico -como otros textos del Seiscientos- recoge la inquietud social por la melancolía y su complementario, la locura, relacionadas frecuentemente con dramas en torno a figuras reales o nobles y su ejercicio del poder como El príncipe melancólico de Lope de Vega y El melancólico de Tirso de Molina. En este trabajo nos interesa indagar cómo se vincula dicha tematización con la percepción teatralizada del mundo y de la vida y con los procedimientos retóricos más significativos mediante los cuales dichas pasiones se manifiestan en una textualidad poco usual para analizar la melancolía hispana: el teatro breve. De este modo, mostraremos de qué manera una pieza menor y risible como el entremés La venta de Francisco de Quevedo se convierte en un dispositivo metateatral que refracta representaciones de un imaginario fuertemente melancólico pero desfiguradas en su variante paródica, desplazando la profundidad de cuestionamientos religiosos, morales o existenciales a planos de comicidad y satirización. El entremés elegido focaliza la acción dramática en una venta o posada, verdadero tópico de la literatura del siglo XVII en general pues constituye el locus folklórico de la miseria y el engaño donde pasan "gato por liebre".
\end{abstract}

\section{Metatheatre, Laugh and Melancholy in La venta by Francisco de Quevedo}

\begin{abstract}
The Baroque Hispanic theatre, like other texts of the Seiscientos, registers the social concern for melancholy and its complement, madness, both of which are often related to dramas feautring royal or noble characters and their exercise of power, such as El principe melancólico by Lope de Vega and Elmelancólico by Tirso de Molina. In this work we are interested in investigating how this thematization is linked with the theatrical perception of the world and of life, and with the most significant rhetorical procedures through which these passions are conveyed in an unusual textuality to analyze Hispanic melancholy: short
\end{abstract}

Palabras clave

entremés metateatro venta risa melancolía

Keywords entremés metatheatre venta laugh melancholy 
1. R. de la Flor (2007: 120) remite a cuatro textos que trazan fundamentales abordajes de la melancolía en el mundo hispano, si bien en momentos muy alejados entre sí: Drama y duelo (Cacciari, 1989), Cultura y melancolía. Las enfermedades del alma en la España del Siglo de Oro (Bartra, 2001), Azabache. El debate sobre la melancolía en la España del Siglo de Oro (Gambin, 2008) y Exorcismos de la memoria. Políticas y poéticas de la melancolía en la España de la Transición (Medina Domínguez, 2001).

2. La referencia a la Anatomía de la melancolía (1621) del inglés Robert Burton es inexcusable en toda aproximación al campo semántico de la melancolía y a su contextualización histórica ya que esta dolencia afectó también a otras naciones europeas (Fumaroli, 2005). No obstante, creemos justo señalar que el texto del médico andaluz Andrés Velásquez, el Libro de la melancolía, es anterior (se publicó en 1585). theatre. In this way, we will show how a minor and laughable piece like the entremés La venta of Francisco de Quevedo becomes a metatheatrical device that refracts representations of a strongly melancholic worldview, although disfigured in its parodic variant; as a result, the depth of religious, moral or existential questions is displaced to comic and satirical settings. In the chosen entremés, the dramatic action is focused on an inn or venta, a significant topic of seventeenth century literature in general, since it constitutes the folk locus of misery and deception where one is sold a pig in a poke.

\section{El teatro de la melancolía}

Si hay algo que caracteriza el imaginario del Barroco hispánico -como dijera Maravall (1975) en su paradigmático estudio-, es la intensa noción de teatralidad que se percibe en textos artísticos y aun de toda índole: la idea de que el mundo es un escenario y de que todos somos actores durante el breve lapso de nuestra existencia. Esta concepción, unida a la de la vida como un sueño en el que no sabemos bien qué es real y duradero y qué, imaginado, halló su cauce natural en el teatro -el ejemplo más claro es La vida es sueño de Calderón- y en la literatura filosófica y moralizante de la época.

Este complejo de imágenes entrelazadas emerge del trasfondo espiritual y religioso del desengaño del mundo, leit motiv de la escritura barroca asociado con el mal melancólico que aquejaba al cuerpo social de la España del 600. Como afirma R. de la Flor:

Todo forma parte en la época de un superior “momento melancólico", compuesto por una real o imaginaria pérdida de sentido -la cual afecta profundamente al conjunto del espacio social-; por una desesperación que, indistintamente, se da como tensión interna e inherente a la vivencia histórica del momento, como opera también sus efectos devastadores en los textos, que alcanzan a vertebrar el imaginario colectivo de un tan grave momento. (Rodríguez de la Flor, 2007: 62)

Ello lo habilita a instalar toda la cultura barroca hispánica en la "órbita fría" de una "era melancólica", que se instaura entre 1580 y 1680, a tal punto que permite hablar de una "melancolía Austria" o "tristeza del tiempo de los Austrias" (2007: 108). Como resultado de este imaginario, aparece una contaminación generalizada, un "tono" presente tanto en el dominio discursivo como en las producciones simbólicas de todo género ya que la agudeza y el ingenio, atributos de dichas producciones, eran una característica de los hombres de letras dominados por la "bilis negra".

R. de la Flor (2007) recuerda que la actual noción de melancolía surge en el área del psicoanálisis, pero se fue bifurcando históricamente desde distintas perspectivas, como "fuerza cultural" y como "tristeza del alma". ${ }^{1}$

Efectivamente, en el siglo XVII el término melancolía remitía a un concepto ambiguo y plurívoco, que daba nombre a una serie de síntomas físicos, conductas y prácticas sociales que escapaban a la idea histórica de normalidad (cfr. Pallares, 2001). La melancolía se había convertido en la primera explicación posible para una diversidad de afecciones que entrañaban tristeza, ensimismamiento, angustia e, inclusive, en su grado máximo, locura. A causa de la pluralidad de dimensiones que abarcaba dicha afección en ese período, Pujante (2008: 402) sostiene que el concepto fluctuaba entre la enfermedad, el carácter nacional y la moda social.

Según los estudios de Burton, ${ }^{2}$ la melancolía podía clasificarse en dos grandes tipos: en disposición o en hábito. La primera, como característica inherente a nuestra condición de seres mortales, es 
esa melancolía transitoria que va y viene en cada ocasión de tristeza, necesidad, enfermedad, problema, temor, aflicción, enojo, perturbación mental o cualquier tipo de cuidado, descontento o pensamiento que cause angustia, torpeza, pesadez y vejación del espíritu y cualquier ánimo opuesto al placer, la alegría, el alborozo, el deleite, que nos causa indolencia o disgusto. (Burton, 2015: 69)

La segunda, en cambio, era un "hábito", una enfermedad crónica, establecida o fija, y también podía ser material o inmaterial, según se tratara de un desequilibrio de los humores o del influjo de Saturno, de razones religiosas, de una pasión frustrada, de hechizos, del exceso de estudio, de emociones como la envidia o la vanidad, de la deformación física....

Dentro del contexto hispánico, el Libro de la melancolía de Velásquez (1585) se ocupaba de refutar el Examen de ingenios de Huarte de San Juan (1575), particularmente en aquellos postulados referidos al humor negro o bilis melancólica. Como afirma Roger Bartra (2001), Velásquez consideraba que su tratado sobre la melancolía era de gran importancia para el "bien público" porque se conectaba con uno de los problemas más acuciantes de la época, la decadencia del imperio y sus causas:

pues no cabe duda de que la España del Siglo de Oro sufrió cambios críticos considerables que dejaron huellas profundas en su evolución. Una de esas huellas fue la melancolía, que podría verse como un signo que anunciaba a los españoles del siglo XVI que el poderoso imperio se acercaba lentamente a su ocaso. (Bartra, 2001: 22)

Por su parte, Ángel Álvarez Solís señala que el quid de la inquietud generalizada de los estudiosos de la época por dicho tema reside en la pregunta sobre si la melancolía era una "enfermedad democrática capaz de traspasar cualquier estamento o condición social” (2015: 79), es decir, en la configuración médica de la república de la melancolía. La lectura política de esta dolencia facultaba que las metáforas médicas ilustraran la declinación del imperio y que las categorías políticas explicaran problemas médicos. Dicha teoría atendía al control de las enfermedades y pasiones, es decir, a la conservación del cuerpo político, ya que

si la melancolía evita que el gobernante tenga control sobre sus pasiones, entonces un gobernante afectado no puede tomar decisiones políticas acertadas, pues solo quien puede gobernarse a sí mismo es capaz de gobernar a los otros. La melancolía se torna así en la enfermedad privada que más afecta la salud pública. Un rey enfermo del alma no está capacitado para encontrar los medios más adecuados para preservar la salud del cuerpo político. (Álvarez Solís, 2015: 82)

Concordando con lo anteriormente expuesto, la melancolía y su complementario, la locura, aparecen frecuentemente en dramas ${ }^{3}$ que problematizan el ejercicio del poder y el autocontrol de figuras reales o nobles como El príncipe melancólico de Lope de Vega, ${ }^{4}$ El melancólico de Tirso de Molina, ${ }^{5}$ Los cabellos de Absalón y La hija del aire de Calderón de la Barca. ${ }^{6}$

No obstante, en esta oportunidad nos interesa indagar cómo se vincula la tematización de la melancolía y la locura con la percepción teatralizada del mundo y de la vida y con los procedimientos retóricos más significativos mediante los cuales dichas pasiones se manifiestan, en una textualidad poco usual para analizar la melancolía hispana: el teatro breve. ${ }^{7}$

No hay en este género personajes de alto rango ni pasiones elevadas (amor, honra, sentimiento del deber) que involucren, con su desbordamiento, una alteración del
3. Incluimos este grupo de textos dentro de los que Arellano denomina obras dramáticas serias (1995: 138).

4. Precisamente, la lectura política de la melancolía de Álvarez Solís es ejemplificada con El príncipe melancólico, que "simbolizó de manera teatral cómo la melancolía interior es producto de la simulación y juego de espejos al que se encuentra sometido el que ingresa, ya sea por voluntad o sin ella, a la Corte real." (Álvarez Solís, 2015: 83)

5. Nosotros observamos aspectos coincidentes en la conducta de Rogerio, devenido duque luego de haber vivido -ignorante de su condición-en una aldea y de haberse enamorado de una rústica joven, quien también pertenece a la nobleza, como se sabe en el desenlace (Sosa, 2018).

6. Dedicamos trabajos al examen de la melancolía en los protagonistas de ambas obras (Cfr. Sosa, 2017; 2019).

7. Esta cuestión enlaza nuestra investigación actual: “Locura, melancolía e imaginario en el teatro barroco español: estrategias de representación" con la anterior: "La metateatralidad en la dramaturgia española del siglo XVII. Parte II. El espejo invertido del metateatro breve" (ambos del Consejo de Investigación de la Universidad Nacional de Salta). 
8. A este inventario debe añadirse el tipo del alcalde bobo, interpretado emblemáticamente por el actor Cosme Pérez, alias Juan Rana. Hablar de él permite incluir también a los comediantes como parte de los tipos sociales marginales de la época.

9. R. de la Flor (2007: 218-219) ejemplifica el "discontento" oculto y disimulado que ocupa el fondo de la realidad de las cosas con el Guzmán de Alfarache de Mateo Alemán: en esta novela la crítica social se construye mediante el sarcasmo y una retórica de la degradación objetual.

10. Desde el seminal artículo de O'Connor (1975) hasta trabajos del hispanismo argentino, recogemos los aportes de Wardropper (1968), Larson (1989), Maestro (2004), por citar solo algunos.

11. “Calderón presenta en su Entremés de la melancolía una intensa y sostenida experimentación metateatral para examinar la visión laberíntica y confusa de la realidad del mundo,

la vida como teatro y el mundo del teatro [...]" (Balestrino, 2016). orden social y político; antes bien, el teatro llamado menor plantea la teatralidad de lo infimo, inclusive marginal, desde la procedencia y el lenguaje de sus personajes (sastres, venteros, pasteleros, criados, sacristanes, soldados, estudiantes, gorronas, rufianes, hampones, prostitutas, alcahuetas, negros, indianos... ${ }^{8}$ hasta la trivialidad del conflicto dramático. Los móviles de la acción suelen ser una burla, una trampa, un hurto... cuando no se trata, simplemente, de trazar un cuadro de costumbres. Hay afán de mofa, búsqueda de satisfacción de instintos básicos y una extensa nómina de vicios y manías (avaricia, codicia, lujuria, gula, prejuicios, obsesiones...), que muestran las flaquezas humanas desde su costado más ridículo y deleznable.

No obstante, una pieza menor y risible como el entremés La venta de Francisco de Quevedo se convierte en un dispositivo metateatral que refracta representaciones de un imaginario fuertemente melancólico pero desfiguradas en su variante paródica, desplazando la profundidad de cuestionamientos religiosos, morales o existenciales a planos de comicidad y satirización. A la conciencia ética de la teatralidad del mundo de personajes nobles o reales obtenida mediante las estrategias del metateatro en grandes comedias, le corresponde la de los personajes burlados y (des)engañados de la esfera degradada de esta y otras ventas entremesiles. En esta conciencia compartida por el espectador se vislumbra, más allá de la risa, un poso de melancolía ante el espectáculo de la irrisión de valores que le devuelve el escenario.?

Abordar el entremés de Quevedo desde la perspectiva señalada implicará, previamente, describir -siquiera en forma sucinta- la metateatralidad y su especificidad en géneros breves.

\section{Metateatralidad y teatro breve}

Como hemos observado en trabajos anteriores sobre metateatro, numerosas obras dramáticas del Barroco refieren al proceso de escritura y/o su condición de artificio escénico mediante estrategias que provocan una ruptura en el ilusionismo teatral. En el ejemplo antes citado, Segismundo es actor involuntario -"nesciente", diría Hermenegildo (1999), en tanto desconoce lo que ocurre- de la escena montada por el rey Basilio al llevarlo a palacio y someterlo a un experimento, para luego transportarlo a "otro escenario", el de la torre, sin solución de continuidad. Tanto el procedimiento como la conclusión a la que arriba el infeliz príncipe forman parte de una diversidad de prácticas dramáticas autoconscientes llamadas metateatro. Al observar el desdoblamiento en escena de actores en espectadores internos (fundamentalmente, Basilio y su ayo), los espectadores del XVII captarían vívidamente, como en un espejo, la idea de que el mundo es un escenario y la vida, un sueño.

Se ha mostrado ya ${ }^{10}$ cómo esta sobreteatralización o reduplicación de la teatralidad se revela como el dispositivo más adecuado -en géneros mayores del teatro barrocopara denunciar la condición problemática de la realidad y el "engaño a los ojos" que padece el hombre ante la misma, con su previsible corolario de (des)engaño y melancolía.

En cambio, el teatro breve -dentro del cual se incluye una variedad tipológica (entremeses, loas, mojigangas...) reunida por el común denominador de su corta extensión y su propósito de entretener (Rodríguez Cuadros, 2000; 2002)-, ese que hacía reír en los entreactos de las obras, sigue siendo una cantera poco examinada en relación con este supuesto. El trabajo de Graciela Balestrino (2016) sobre el Entremés famoso de la melancolía, atribuido a Calderón, constituye un punto de partida para las presentes indagaciones ${ }^{11}$. 
Asimismo, las investigaciones realizadas sobre un corpus heterogéneo ${ }^{12}$ de textos breves de distintos autores han permitido reconocer una extensa gama de modalidades metateatrales que están conectadas con la condición de liminalidad de aquellos: apertura de la totalidad del espectáculo, ${ }^{13}$ bisagra entre las partes de la obra mayor y fin (gradual) de la ficción.

El (meta)teatro breve replica en forma contrapuntística las convenciones del género mayor que lo contiene mientras va operando rupturas en el ilusionismo del espectáculo en su conjunto mediante el ambiguo juego realidad/ficción: actores que devienen personajes ante la vista del público, tematización de la vida del artista, duplicación del mismo intérprete en roles cómicos y serios inmediatamente sucesivos, puesta en escena del ensayo de la obra que supuestamente se verá a continuación... Al hacerle ver al espectador el envés de la ficción y remarcar de este modo la naturaleza artificial de la representación, se establece con él un grado superior de cooperación y complicidad.

Laurent Gobat utiliza la metáfora del espejo -de larga tradición en la reflexión metaficcional- para definir el efecto de desestabilización que provoca la obligada complicidad a la que fuerza el metateatro:

¿Qué son los encajamientos sucesivos del metateatro sino espejos utilizados simultáneamente y de manera concertada para desestabilizar al espectador? Perdido entre juegos de espejos, este duda de la ficción, duda de la realidad del mundo, y duda incluso, [...] de su propia realidad de espectador. (Gobat, 1997: 92)

En el caso del teatro breve, la metateatralidad permite canalizar, a través del carácter jocoso de este último, problemáticas serias y acuciantes de la época-verbigracia, la obsesión de la honra en El retablo de las maravillas cervantino-; por ello, no es extraño que aparezcan abundantes referencias a males sociales como la melancolía y la locura, si bien desde la estética distorsionada de un espejo invertido. ${ }^{14}$

En forma semejante a la "matemática perfecta de los espejos cóncavos" valleinclaniana, ${ }^{15}$ procedimientos como la parodia y el uso del grotesco en el teatro breve del XVII a menudo llevan a cabo una deformación de la imagen de lo real, produciendo en el destinatario efectos de distanciamiento pero también de extraña familiaridad, de risa pero, al mismo tiempo, de indefinida inquietud. Como esa incómoda sensación que nos invade cuando nos enfrentamos a una imagen especular que distorsiona nuestra apariencia y nos reconocemos a medias. Es decir, que en el (meta)teatro breve se produce una segunda forma de desestabilización lograda por el grotesco.

En consonancia con el cometido de suscitar el estremecimiento que, según Kayser (1964), singulariza lo grotesco, ${ }^{16}$ la comicidad originada por la situación y los tipos humanos puestos en escena daría paso, casi imperceptiblemente, al cumplimiento de la intención ulterior de la sátira: "corregir los vicios mediante una censura moral que utiliza 'el medio instrumental (a menudo convertido en desviación perniciosa y exclusiva) de la graciosidad'“(Arellano, 2006: 336).

Alfonso Rey, a propósito de la misma cuestión, encuentra dos tipos de risa que provienen de la formación cristiana de Quevedo: "una es la intrascendente y juguetona, que aligera la predicación: otra, más severa, la del justo que se burla del pecador necio" (2006: 239).

En el caso específico del entremés de Quevedo, con asunto similar a los de otros textos, ${ }^{17}$ focaliza la acción dramática en una venta o posada, verdadero tópico ${ }^{18}$ de la literatura del siglo XVII pues constituye el locus folklórico de la miseria y el engaño donde pasan "gato por liebre". La reprehensión moral adopta la forma "intrascendente
12. Citamos algunos de los textos de dicho corpus, constituido básicamente por entremeses, loas y mojigangas: La portería de las damas y El plenipapelier de Francisco de Avellaneda, El triunfo de Juan Rana de Calderón de la Barca, El ensayo de Andrés Gil Enríquez, Lo que pasa en una venta de Luis de Belmonte, La ballena de Antonio de Monteser, Lo que pasa en mitad de la Cuaresma al partir la Vieja, Entremés de la Perendeca de Agustín Moreto. 13. Remitimos a un trabajo anterior en el que nos detuvimos en estas características a propósito de la Loa entremesada para la compañía del Pupilo (Sosa, 2013).
14. Retomamos la expresión del título de la investigación citada ut supra. En un futuro exploraremos las relaciones entre la imagen distorsionada del espejo en el teatro breve con el procedimiento pictórico de la anamorfosis. Como una sugestiva línea a seguir, $\mathrm{R}$. de la Flor habla de anamorfosis a analizar la deconstrucción de un retrato de Sor Juana $(2007,366)$ y remite a Nicolás (1986), quien estudia las anamorfosis en Quevedo. 15. El propio Valle-Inclán admitió la filiación de su esperpento con la estética del grotesco quevediano.

16. "El estremecimiento se apodera de nosotros con tanta fuerza porque es nuestro mundo cuya seguridad prueba ser nada más que apariencia" (Kayser, 1964: 225). 17. Hay otras piezas que permiten idéntica observación (Lo que pasa en una venta de Luis de Belmonte Bermúdez, El reloj y genios de la venta de Calderón, Entremés del ventero de Luis Quiñones de Benavente), pero que no tratamos aquí por razones de espacio. 18. Arellano y García Valdés (2006) introducen así su edición del entremés de Quevedo: “La venta es un gracioso cuadro costumbrista que se desarrolla en una venta de camino, ambiente que se encuentra en otros entremeses y en algunas novelas picarescas. [...] La realidad de las precarias condiciones de las ventas del camino y la rapacidad de los venteros llegaron a ser tópicas en la literatura." Navarro Durán (2012), al tratar sobre pícaros, ninfas y rufianes en la Edad de Oro, dedica un capítulo a "Descansos en el camino", en el que las ventas constituyen por antonomasia el lugar de la truhanería y el fraude. 
19. Este aspecto se desarrollará posteriormente al analizar el teatro en el teatro del entremés.
20. Por integrar también este grupo de aves, la criada, denominada Grajal, reúne parecidos rasgos semánticos: de hecho, también se conoce a la corneja con el nombre de grajo. y juguetona" de la risa, de la parodia y el grotesco, con el propósito de desnudar los vicios concentrados en la microesfera de la venta, lugar de tránsito y tráfico de toda clase de individuos -aun los más marginales- de la España del Seiscientos. El metateatro vendría a coadyuvar a este efecto con una serie de modalidades que enfrentan simultáneamente a los espectadores -internos y externos ${ }^{19}$ a las experiencias del engaño y su posterior desengaño.

\section{Entre truhanes}

A fin de comprobar nuestra hipótesis, en primer lugar revisaremos brevemente la intriga del texto quevediano:

»En la venta el huésped Corneja sale con un gran rosario, terminando de rezar. Extraescena, se oye el canto socarrón de la criada, Grajal, con pullas hacia aquel. Corneja sale y protesta contra ella. Se aprestan a recibir a los viajeros. Nuevo canto de Grajal (referencias a la comida indigerible y a la laya rateril del ventero).

» Se va Grajal y llega un estudiante que se aloja en la venta. Diálogo sobre la pésima comida, en la que nada es lo que parece. Alusión del estudiante a la condición mora del ventero.

» Relato de Grajal acerca de la comida grotesca de los arrieros.

» Un mozo de mulas pide un jarro de azumbre a Corneja. En ausencia de este, el mozo galantea a Grajal (parodia de los lugares comunes de la lírica amorosa).

»Vuelve el estudiante y discute con Corneja el pago por la miserable comida.

" Llega Guevara con su compañía de farsantes. El pedido de una función se dilata hasta después de la cena. Las pullas entre el ventero y el estudiante se zanjan con el canto por parte de todos.

La semejanza entre este y otros entremeses sobre ventas es notable: siempre exhiben situaciones y personajes cuya sola aparición permitía al público reconocer el tenor y desenlace de la pieza. Ante los ojos del espectador cómplice, se operaba una sobreteatralización de la venta escenificada: esta se convertía en tablado de una microacción dramática de engaño o burla, que se repetía con ligeras variantes, y cuyo objeto era el o los desprevenidos viajeros que llegaban al mesón. El protagonista -aunque contara con la ayuda de la criada o aliados ocasionales- era primordialmente el ventero, delineado por sus atributos básicos, la cicatería y el hurto. Hay aquí un primer componente propio del metateatro: el personaje autorreferencial que sale del texto donde fue ubicado inicialmente para migrar a otros.

En el entremés La venta, la figura prototípica del ventero alcanza nuevos matices de deformación/degradación. En primer lugar, la caracterización negativa está determinada desde el nombre mismo de Corneja, asociado con los malos augurios y el carácter depredador de esta ave carroñera, ${ }^{20}$ por otra parte, es presentado como un santurrón hipócrita, con un gran rosario que evocaría, a espectadores y lectores discretos, otros personajes quevedescos como el licenciado Cabra, lo cual contrasta aún más con la amoralidad de que hará gala posteriormente.

Veamos el primer y sintomático ejemplo de estos atributos aparentemente contradictorios:

Sale Corneja, vejete, con un rosario, y canta dentro Grajal.

Corneja Mas líbranos del mal, amén, Jesús.

Grajal Canta. ¿Es ventero Corneja?

Todos se guarden, que hasta el nombre le tiene 
de malas aves.

¿Qué harán las ollas

donde las lechuzas

pasan por pollas? $(\mathrm{vv.2-8})^{21}$

Para completar el retrato, se añade al ventero la sospecha de moro o morisco. En una discusión, Corneja le desea al Estudiante que desaparezca en tierra de moros y este le contesta: "-¿Eso pasa? Yo vendré a discurrir a aquesta casa" (vv. 45-46). Por ello no es casual que, encubriendo su peor miedo, el ventero desee a otros el castigo inquisitorial destinado a criptomusulmanes o judíos; para que Grajal deje de cantar, la amenaza con la dilogía “-¡En malos potros de verdugo cantes!". No olvidemos la condición de cristiano viejo de Quevedo al evaluar esta característica; ${ }^{22}$ el poeta no ha escatimado pinceladas lóbregas sobre el personaje, yendo de la comicidad a una sátira feroz.

En cuanto al engaño prototípico, este consiste en la comida indigerible que se ofrece en las ventas en la que nada es, no solo lo que parece, sino lo que se dice que es. En el texto quevediano, el tópico también se singulariza con ribetes grotescos. Veamos la narración ${ }^{23}$ que hace la criada Grajal de una escena in absentia, o sea, que no se ha representado ante los ojos de los espectadores:

$\begin{array}{lc}\text { Corneja } & \begin{array}{c}\text { Diste a los arrieros y a los carros } \\ \text { de cenar? } \\ \text { Grajal }\end{array} \\ & \begin{array}{c}\text { Ya encajé toda la historia; } \\ \text { comiendo están a tiento sabandijas. }\end{array} \\ \text { Corneja } & \text { Cuéntame aquesa lucha. } \\ \text { Grajal } & \text { Oye la comezón. } \\ \text { Corneja } & \text { Empieza } \\ \text { Grajal } & \text { Escucha. }\end{array}$

Luego que por manteles,

les puse, con perdón, los arambeles, y la sal en un plato,

un cuchillo sin cabo, un pan mulato, un jarro desbocado

tan sucio y sin adorno,

que pudo tener vino de retorno, ${ }^{24}$

y en el vidrio volviose

vinagre de la esponja...

«¿Es bueno?», preguntaron. Yo a lo monja

respondí, muy fruncida de apariencia:

"Por bueno se lo dan, en mi conciencia».

Sentáronse en arpón ${ }^{25}$ en un banquillo,

tocaron a colmillo;

arremangaron todos los bigotes

por no los enramar con almodrotes; ${ }^{26}$

metiles la vianda;

templaron las quijadas los cuitados,

para hacer consonancia a los bocados; [...]

21. De ahora en adelante, citaremos por la edición de Arellano y García Valdés (2006).

22. En El buscón (capítulo V, “De la entrada en Alcalá, patente y burlas que me hicieron por nuevo"), también don Pablos llegará a una posada y su huésped es un morisco de dudosa catadura (Quevedo, 2005).

23. Afirma Julio (1996) que en el texto dramático del Siglo de Oro el intercambio verbal que se produce en las tablas no se limita a la simple transmisión de información dialogada, sino que alude a aspectos espacio-temporales y de acción que no siempre se visualizan en escena, que se expresan a través de la descripción (decorado verbal, caracterización verbal de personajes ausentes) y la narración (presentación de antecedentes históricos del drama, presentación de una acción no visualizada e inclusión de cuentos o ejemplos).

24. Arellano y García Valdés (2006) anotan que la expresión vino de retorno (v. 97) proviene de las "mulas de retorno", que eran las que volvían vacías de un viaje y aceptaban cargas baratas; pero vino de retorno es el orinado, es decir, que el jarro era tan malo que podía servir de orinal. 25. Aunque los editores del entremés no aciertan a descifrar el sentido, nos inclinamos a pensar que significa "a horcajadas", ya que los comensales se sientan en un banco.

26. Es un tipo de salsa según los editores.

Hubo unos mascadores de montante, que, tirando a dos manos de un pedazo, devanaban las tripas en oveja.

Hay comedor con pujo que se queja,

y, los puños cerrados,

oye crujir los dientes. [...]

Mas nada se compara con aquellos

a quien les cupo en suerte la morcilla 
27. “Entendemos, entonces, que la incorporación de elementos narrativos [...] duplica temáticamente la obra principal [...] porque subvierte las relaciones de mirantes y mirados propias de la comedia autoconsciente, generando un relato especular que, por estar en escena, deja al descubierto su doble destinación puesto que, en este caso, la dialéctica narrador-narratario queda redefinida como una relación tripartita de narrador-narratario-narratario archimirante." (Herrera, 2012: 299-300).

28. Continuando la propuesta terminológica de Hermenegildo, TeT y TsT, proponemos esta categoría como una variante del primer grupo (cfr. Hermenegildo, 1999).

29. Cfr. en la edición de Arellano de Los sueños de Quevedo (1991).

30. Hemos comprobado que no es la primera ocurrencia de este procedimiento.

31. Recordemos que dentro de la categoría de TeT puede incluirse un baile, carnaval, mimodrama... siempre que al menos uno de los actores de la pieza encuadrante se transforme en espectador de la encuadrada en algún momento. Al verse espejado en ese 0 esos espectadores internos, el espectador externo experimenta

la conciencia de teatralidad y el efecto de distanciación.

\author{
Metiéronle el cuchillo; aquí fue Troya, \\ que se dividió en ruedas, \\ con algunas colores sospechosas. \\ "No entiendo esta morcilla», dijo el uno. \\ Otro, santiguador de los mondongos, \\ decía: "A cieno sabe. ¿Si es de estanque?» \\ $Y$ dijo otro, con boca derrengada: \\ "Busquen su descendencia a la morcilla \\ y darán con un mulo de reata, \\ que es menester saber de quién desciende, \\ de rocín o de oveja: \\ bástale ser morcilla de Corneja». (vv. 86-143) [Cursivas nuestras]
}

Retomando a Abuín González (1997), Alejandra Herrera (2012) recupera la noción de narrador en el teatro que, si bien refiere al universo más complejo de la comedia, nos será útil como punto de partida para el análisis de este segmento. ${ }^{27}$ Es decir que en el texto existe otro componente metateatral de relevancia, la inserción del relato de la comida de los arrieros, por boca de Grajal, quien es al mismo tiempo narrador interno y actriz pues relata y mima su propia actuación dentro de la acción relatada. Podemos hablar, entonces, de una variante del teatro en el teatro: la narrativa en el teatro $(\mathrm{NeT}),{ }^{28}$ que instituye un narratario interno (el ventero) y un narratario archimirante (el auditorio).

¿Cuál es la función de este procedimiento metateatral? Como sostiene María Teresa Julio (1996: 201), la narración recrea "una acción descrita por un personaje que ve más que los otros y que incorpora verbalmente acontecimientos que supuestamente están sucediendo en el mismo momento de la representación, pero que no tienen cabida en las tablas". Quizá el breve espacio del entremés impidiera el desarrollo de tal escena o, simplemente, el lenguaje evoca un grotesco tan despiadado que toda representación física resultaría insuficiente o, por el contrario, fuera de los límites del decoro.

Corroborando esta última hipótesis, el grotesco sugerido por el relato se acentúa en otra secuencia, donde Grajal -quien, además de participar de la índole rapaz y socarrona de su amo, es bonita- aconseja al enamoradizo mozo de mulas no "morir de amor", so pena de que su carne forme parte del próximo menú (escarnio parecido al que Quevedo prodiga a los pasteleros en el Sueño del infierno). ${ }^{29}$

El tercer componente al que dedicaremos nuestra atención -y que muestra una gradación de la metateatralidad-aparece en la última escena ya que, como afirman los editores del entremés, all “ “[...] Quevedo introduce el teatro en el teatro: ${ }^{30}$ se pide a la compañía de cómicos de Guevara (de paso para Granada) que dé una fiesta" (Arellano y García Valdés, 2006: 347). Esta fiesta será el baile final, que consiste en una jácara titulada "Carta de la Perala a Lampuga, su bravo", de la que se incluyen solamente los cuatro primeros versos pero que, por su fama, era muy conocida. Por lo tanto, no hacía falta más para asociar al ventero y su criada con el mundo hampesco. De manera irónica, los cómicos representan una piececita de rufianes y ladrones que confirma -en vez de refutar las acusaciones del Estudiante- el engaño del que se ha hecho objeto a los personajes anteriormente, transformándose en una mise en abyme de carácter retrospectivo pues, al estar al final, se erige en corolario de la acción del texto encuadrante. ${ }^{31}$

Por otra parte, la referencia intratextual a una jácara compuesta anteriormente por parte del dramaturgo recuerda al espectador la naturaleza ficcional del espectáculo y su origen literario, rompiendo con el ilusionismo teatral. 


\section{4. "Este mundo es venta"}

Otra referencia intratextual, la letrilla satírica $N^{\circ} 647$ de Quevedo, nos sirve para relacionar las ideas expresadas y esbozar unas conclusiones, siquiera provisorias: "Toda esta vida es hurtar, / no es el ser ladrón afrenta, / que como este mundo es venta, / en él es proprio el robar" (vv. 3-6).

La significación del entremés se expone con claridad meridiana en la metáfora del mundo como venta, símil que aparece en otros escritores de la época como el sevillano Rodrigo Fernández de Ribera (1579-1631), autor de la narración satírico-alegórica $E l$ mesón del mundo (1631), que cuenta lo que ocurre en un mesón que representa la vida, en la que se entra al nacer y se sale al morir.

Al hablar de la percepción barroca de la existencia humana, entonces, es válido el tópico del mundo como teatro pero también como casa de locos o mesón (Maravall, 1975) [cursivas nuestras]. La equivalencia entre mesón y tablado es evidente. ${ }^{32}$ Volviendo al entremés quevedesco, la venta-lugar emblemático a la vera o cruce de los caminos-, es un mundo abreviado, donde transitan y trafican los más diversos individuos (desde el noble hasta los cómicos o las prostitutas). En venta y ventero el fraude y el hurto se encarnan proverbialmente, como hemos intentado mostrar, destacándose la miseria del establecimiento -las chinches pueden "ejecutar" a toda una compañía- y de la comida -lo falaz e indigerible habla de una nula alimentación- ${ }^{33}$, verdaderas metonimias de las condiciones paupérrimas de la sociedad hispana del XVII.

La risa de la pieza cómica lograda por la sobreteatralización del género metateatral no encubre la punzante sátira del poeta de comedias sobre un fragmento de esa decadente España aurisecular. Bajo la capa de la hilaridad, el embuste y la burla imperantes en la posada constituyen otra forma de articular la crítica y la "reprensión moral y festiva de los desórdenes públicos", como diría Quiñones de Benavente, ${ }^{34}$ propias del teatro breve. Así como el frontispicio de la tercera edición de Anatomía de la melancolía (1628) muestra, entre sus estampas, la imagen de Demócrito para aludir a la actitud del autor frente a la temática planteada, ${ }^{35}$ el entremés quevediano ostenta la opción de la risa para combatir la enfermedad social. Deseamos volver a Álvarez Solís, quien asevera:

Si el mundo es un meta espacio donde existen actores y espectadores, el papel actuado por cada individuo es transitorio y, en consecuencia, tiene la opción de sufrir con el personaje -vivir con humor melancólico-o gozar lo mayormente posible la breve estadía que significa el mundo... [...] La subjetividad barroca no es una conciencia exclusivamente trágica ni tampoco directamente cómica, más bien es una conciencia que se determina con base en las circunstancias que enfrenta: una conciencia tragicómica, dualista y engañosa. [...] Esta elección subversiva entre el llanto de Heráclito o la risa de Demócrito permite que el conflicto y la contradicción sean los pivotes cognitivos para que el mundo adquiera su propia conservación. (2015: 43-46, cursivas del autor)

Pero en La venta el alcance de sátira y metateatro llegan aún más allá. La "comida imaginaria", en la que nada es lo que parece, constituye el ápice del sentimiento de inanidad y de percepción de la falsedad de las apariencias.

La "fiesta" final con canto y las agudas chanzas con que se cierra la acción dramática en el entremés disimulan, a través del espejo deformante de la parodia y el grotesco, el imaginario melancólico que palpita bajo la acerba denuncia sobre la caducidad de todo lo existente, incluidas las glorias imperiales. Como una imagen distorsionada
32. La relación con la casa de locos queda para futuros trabajos.

33. En otro trabajo sobre Lo que pasa en una venta, señalamos esta cualidad a propósito de la “comida imaginaria” (Sosa, 2016).

34. Según Martínez (1998), el género entremesil ejerce una crítica de finalidad moralizante pues pretende "reprehender los vicios y defectos públicos", a pesar de producir un efecto divertido.

35. Al respecto, Starobinski (2016) analiza esta portada estableciendo conexiones entre la visión melancólica del mundo representada por Heráclito y la respuesta de la risa satírica aportada por Demócrito. 
36. También R. de la Flor (2007: 182) encuentra eficaz la imagen del espejo: “Así, la época se lee mejor en un espejo de azogue arañado y confuso, anfibológicamente desgarrado, en cuanto apunta hacia lo que definitivamente es inaccesible en la escena". por un espejo cóncavo, ${ }^{36}$ la venta quevediana se convierte en una cifra, en un signo más o menos enigmático del "engaño a los ojos" que padece el hombre ante la realidad, revelando al mismo tiempo el problema metafísico que implica la aprehensión de esta.

De la risa a la melancolía, entonces, media solo un paso, el mismo que, inversamente, ha recorrido el poeta para construir su dispositivo metateatral. El complejo artificio de imágenes reflectantes, con su efecto desestabilizador, reenvía al "ingenio" melancólico que lo creó.

R. de la Flor explica el oxímoron de la "risa melancólica" del Barroco hispánico con meridiana claridad:

Entonces, el Ilanto heraclíteo se ve sustituido por la risa de Demócrito, al fin manifestación última y sofisticada de la misma malencolía, a la cual descarga de pesadumbres, aunque, ciertamente, no de razón. [...] Quizá el siglo de la búsqueda de sentido y del conocimiento del mundo tenga en estos dos peregrinos filósofos -Heráclito, Demócrito- los más elocuentes emblemas que modelizan la vida del sabio, y que sintetizan las posturas de sujeto frente al problema del ser y el conocer, constituyendo ambos dos [sic] la misma cara de una constituyente melancolía. Demócrito y Heráclito resuelven en la Risa y en el Llanto la angustia del mundo, convirtiéndose en su resumen, en el rostro de la experiencia de la mundanidad. (2007: 376-378, cursivas del autor)

Por el mecanismo de denegación que opera en todo espectáculo -que permitía al público español reconocer el contexto representado y al mismo tiempo tomar distancia en tanto ficción-, podemos entender ahora el carácter indispensable del género breve como práctica social: reír para no llorar, verdadero antídoto contra la profunda melancolía desatada por el desengaño del mundo, antes de que todo se disolviera "en tierra, en humo, en polvo, en sombra, en nada". 


\section{Dibliografía}

» Abuín González, Á. (1997). El narrador en el teatro. La mediación como procedimiento en el discurso teatral del siglo XX. Santiago de Compostela: Universidade de Santiago de Compostela.

»Álvarez Solís, Á. O. (2015). La república de la melancolía. Política y subjetividad en el Barroco. Adrogué: Ediciones La Cebra, 1a․ ed.

»Arellano, I. (1995). Historia del teatro español del siglo XVII. Madrid: Cátedra.

"Arellano, I. (2006). "Las máscaras de Demócrito. En torno a la risa en el Siglo de Oro”. En: Arellano, I. y Roncero, V. (eds.), Demócrito áureo. Los códigos de la risa en el Siglo de Oro. Sevilla: Renacimiento, 329-359.

»Balestrino, G. (2016). “Parodización del imaginario barroco: tristeza y metateatro en el Entremés famoso de la melancolía de Calderón”. XXV Congreso Internacional de Teatro Iberoamericano y Argentino (Buenos Aires, 2016), GETEA- UBA. Inéd.

"Bartra, R. (2001). Cultura y melancolía. Las enfermedades del alma en la España del Siglo de Oro. Barcelona: Anagrama.

"Burton, R. (2015). Anatomía de la melancolía. Prólogo y selección de A. Manguel. Madrid: Alianza Editorial, $2^{2}$. ed. [ed. orig., 1621].

》Cacciari, M. (1989). Drama y duelo. Madrid: Tecnos.

» Fernández de Ribera, R. (1979). Los anteojos de mejor vista; El mesón del mundo. Edición de V. Infantes de Miguel. Madrid: Legasa.

» Fumaroli, M. (2005). "La mélancolie et ses remèdes: la reconquête du sourire dans la France classique". En: Clair, J. (dir.), Mélancolie, genie et folie en Occident. Paris: Gallimard, 210-224.

»Gambin, F. (2008). Azabache. El debate sobre la melancolía en la España de los Siglos de Oro. Presentación de Aurora Egido. Prólogo de Giulia Poggi. Traducción de Pilar Sánchez Ortín. Madrid: Biblioteca Nueva.

" Gobat, L. (1997). “Juego dialéctico entre realidad y ficción: El retablo de las maravillas de Cervantes”. En: Andrés-Suárez, I. et al., El teatro dentro del teatro: Cervantes, Lope, Tirso y Calderón. Madrid: Verbum, 73-97.

» Herrera, A. (2012). "Entre dimes y diretes. La función metateatral del relato en El escondido y la tapada de Calderón de la Barca". En: Balestrino, G. y Sosa, M. (eds.), Letras del Siglo de Oro Español. Salta: EUNSA-INSOC, 299-303.

» Hermenegildo, A. (1999). "Mirar en cadena: artificios de la metateatralidad cervantina”. En: Hart, C. P., Hermenegildo, A. y Oliva, C. (coords.), Cervantes y la puesta en escena de la sociedad de su tiempo. Murcia: Universidad, Servicio de Publicaciones, 77-92.

» Huarte de San Juan, J. (1575). Examen de ingenios para las ciencias. Baeza: Juan Bautista de Montoya.

» Julio, M. T. (1996). "La diégesis en la mimesis: el relato en el teatro de Rojas Zorrilla”. En: Arellano, l. et al. (coord.), Studia Aurea: Actas del III Congreso de la AISO (1993), Vol. 2, 197-204.

» Kayser, Wolfgang (1964). Lo grotesco: su configuración en pintura y literatura. Buenos Aires: Nova. 
"Larson, C. (1992). "El metateatro, la comedia y la crítica: hacia una nueva interpretación". En: Vilanova, A. (coord.), Actas del X Congreso Internacional de Hispanistas (1989), Vol. 2, 1013-1019.

»Maestro, J. (2004). "Cervantes y Shakespeare: el nacimiento de la literatura metateatral”. Bulletin of Spanish Studies, LXXXI, 4-5, 599-611.

»Maravall, J. A. (2012). La cultura del Barroco. Barcelona: Ariel [1ª ed., 1975].

» Martínez, M. J. (1998). "Sátira y entremés en el siglo XVII”. En: García de Enterría, M. C. y Cordón Mesa, A. (eds.), Actas del IV Congreso Internacional de la Asociación Internacional Siglo de Oro (1996), Vol. 2, 1017- 1022.

»Medina Domínguez, A. (2001). Exorcismos de la memoria. Políticas y poéticas de la melancolía en la España de la Transición. Madrid: Libertarias.

"Navarro Durán, R. (2012). Pícaros, ninfas y rufianes. La vida airada en la Edad de Oro. Madrid: EDAF.

»Nicolás, C. (1986). Estrategias y lecturas. Las anamorfosis de Quevedo. Extremadura, Ediciones Universidad de Extremadura.

»O'Connor, T. A. (1975). “Is the Spanish Comedia a Metatheater?" Hispanic Review, XLII, 275-289.

»Pallares, B. (2001). "La melancolía como enfermedad en la obra de Tirso de Molina (contribución a su estudio)". En: Dolfi, L. y Galar, E. (eds.), Tirso de Molina: textos e intertextos. Actas del Congreso Internacional. Madrid/Pamplona: Instituto de Estudios Tirsianos, 125-178. En: http://hdl.handle.net/10171/38151; obtenido el 07/06/2018.

»Pujante, D. (2008). "La melancolía hispana, entre la enfermedad, el carácter nacional y la moda social”. Revista de la Asociación Española de Neuropsiquiatría, XXVIII, 102, 401-418. En: https://www.redalyc.org/pdf/2650/265019651012.pdf; obtenido el 22/01/2020.

"Quevedo, F. de (1845). "Carta de la Perala a Lampuga su bravo (Jácara III)", Obras festivas, T. II. Madrid: F. de P. Mellado Editor, 62-65.

"Quevedo, F. de (1981). Poesía original completa. Edición de J. M. Blecua. Barcelona: Planeta.

»Quevedo, F. de (1991). Los sueños. Edición e introducción de I. Arellano. Madrid: Cátedra.

»Quevedo, F. de (2005). El buscón. Edición de D. Ynduráin. Madrid: Cátedra, 13ª ed.

»Quevedo, F. de (2006). Entremés de la venta. Edición de I. Arellano y C. García Valdés, La Perinola, 10, 345-360.

» Rey, A. (2006). "La comicidad en la obra de Quevedo. Cuestiones preliminares”. En: Arellano, I. y Roncero, V. (eds.), Demócrito áureo. Los códigos de la risa en el Siglo de Oro. Sevilla: Renacimiento, 235-261.

»Rodríguez Cuadros, E. (2000). “La sonrisa de Menipo. El teatro breve de Calderón ante su cuarto centenario”. En: García Lorenzo, L. (ed.), Estado actual de los estudios calderonianos. Kassel: Festival de Almagro-Reichenberger, 99-186.

»Rodríguez Cuadros, E. (2002), Calderón. Madrid, Síntesis.

»Rodríguez de la Flor, F. (2007). Era melancólica. Figuras del imaginario barroco. Barcelona: José de Olañeta /Universitat de les Illes Balears. 
» Sosa, M. (2013). “La Loa entremesada para la Compañía del Pupilo, en los bordes de la teatralidad”. En: Sikora, M. y Rodríguez, M. (eds.), Representaciones y acontecimientos. Buenos Aires: Galerna, 97-105.

"Sosa, M. (2016). “De embustes y ventas abismales: desengaño, metateatro y metonimia en Lo que pasa en una venta de Belmonte", XXV Congreso Internacional de Teatro Iberoamericano y Argentino (Buenos Aires, 2016), GETEA- UBA. Inéd.

"Sosa, M. (2017). "Hacia una poética barroca de las pasiones: melancolía, culpa y expiación en Los cabellos de Absalón de Calderón de la Barca". En: Nállim, M. E. y Gauna Orpianesi, M. L., El Siglo de Oro Español en Mendoza: recorrido por la obra cervantina y la de otros escritores áureos desde la mirada de especialistas nacionales y extranjeros. Universidad Nacional de Cuyo: Secretaría de Ciencia, Técnica y Posgrado. Libro digital, PDF.

"Sosa, M. (2018). "Bajo el imperio de la melancolía: la retórica teatral de lo efímero en El melancólico de Tirso de Molina". En: Mirande, M. E., Siles A. y Quintana M., Los nortes del hispanismo: territorios, itinerarios, encrucijadas. UNJu/Asociación Argentina de Hispanistas/Agencia Nacional de Promoción Científica.

"Sosa, M. (2019). "Monstruos de los abismos barrocos. La violencia de las pasiones en La hija del aire de Calderón”, Jornaler@s, 4, UNJu, 474-486.

»Starobinski, J. (2016). La tinta de la melancolía. Trad. de A. Merlín. México: Fondo de Cultura Económica.

»Velásquez, A. (1585). Libro de la melancolía. Sevilla: Hernando Díaz.

»Wardropper, B. (1970). “La imaginación en el metateatro calderoniano”. En: Magis, C. H. (ed.), Actas del III Congreso Internacional de Hispanistas (1968). México: El Colegio de México, 923-930. 
